\title{
The Fusion of Modern and Indigenous Science and Technology: How Should It Be Done?
}

\author{
Anamuah-Mensah, $\mathbf{J}$ \\ University of Education, \\ Winneba, Ghana \\ and \\ Asabere-Ameyaw, A \\ Faculty of Science Education, University of Education, \\ Winneba, Ghana
}

\begin{abstract}
Several African intellectuals, especially educators, have realized the need for the overhauling of Africa's educational systems to enable these intellectuals address the needs of Africans. In this paper, we have reechoed the need for this overhauling process, and have argued for an integration of indigenous knowledge systems with the formal school curriculum. In this paper, the benefits of integrating community science and technology with school science and technology and the constraints to the integration have been outlined. It also reports on the attempt at integration by the Centre for School and Community Science and Technology Studies (SACOST), at the University of Education, Winneba in Ghana. SACOST is a centre of excellence established by the African Forum for Children's Literary in Science (AFCLIST), a non-governmental organization. The paper identifies the community as having four major operating areas (the school, indigenous, informal and formal), each of which constitutes a group with shared interests, values and modes of operation. The model proposed for the integration focuses on the school as the central component that should utilize all the existing knowledge in the community in the human resource development.
\end{abstract}

\section{Introduction}

A diverse and growing body of opinion points to the need for an overhaul of Africa's public educational systems to address the needs of Africans (e.g. Brown-Acquaye, 2001; Noye, 2001; Erinosho, 2001). The overhauling of Africa's educational systems for sustainable development in this era, however, should hinge on the cultivation of a strong science and technology base. African countries, through various meetings and fora, have since independence endorsed science education as the wheel for meeting their needs and aspirations. It is believed that failure to recognize the role of the existing knowledge in the community in the promotion of science and technology education has adversely affected the development of a science culture in Africa. Forging links between community knowledge and Western science knowledge may hold the key to sustainable development of Africa. In this light, Brown-Acquaye (2000) asserts that "each is necessary and none is redundant". It is imperative to adopt a holistic approach at addressing our educational needs. The integration of every knowledge available (indigenous, informal and formal) in the community for an all embracing educational system that would cater for the needs of African societies is imperative. However, a number of constraints including old prejudices may have to be confronted in order to achieve maximum benefit 
from the union. The object of this paper is to propose a model for the integration of school and community science and technology education for the effective teaching and learning of functional science in African schools.

\section{Orientation of formal science education}

The western science education introduced by colonial powers in African schools, colleges and universities sought to inculcate Western ideas in the colonized people. For example, the teaching-learning materials and syllabuses imposed on African countries were the exact replicas of those used in the metropolitan centres. Africans were also made to be consumers of the products of Western technologies. Indigenous Africans who behaved, dressed, spoke and acted like the white man were given the greatest honour, even by their fellow Africans. To promote this cultural assimilation policy, and at the same time maintain their dependence on outside inputs, structures needed for knowledge documentation and propagation and material production were not the priority of the African colonial lords, hence African countries had no opportunity to generate new knowledge or produce needed items themselves. This created a situation that compelled the colonized African countries to continue to depend on their colonial lords for science and technology, and their products. This outward orientation of western science education was also evident in the fact that its standards were set in metropolitan centres while its ultimate objective was to serve the needs of the colonial masters. Overseas postgraduate studies tended to, and continue to, be more in the interest of the host country since the content offered for study reflects the needs of the host country, and in many instances are not of immediate relevance to the needs of the developing world, including African countries.

In a nutshell, the Western science that is practised in our schools, polytechnics, universities and its application in the formal economy even though served to integrate African countries into the global knowledge system, it has brought about cultural alienation of the African people making them dependent on the values and belief systems of the West. This form of science, referred to as Western Science because of its historical origin, is viewed as a body of knowledge and ways of generating that knowledge about our world and ourselves. It is highly organized and hierarchically and chronologically structured and covers the science practised in research laboratories, institutions of learning and in industries and promoted by science subject associations and organizations.

A problem militating against the utilization of science for the common good of our nations is the restricted view of science as Western modern science or formal science thereby precluding the indigenous knowledge and know-how existing in our countries, which, to many science educators, constitute science. This view recognizes formal science as the only legitimate knowledge system that all societies should have. Thus, the education we received from the colonial masters led to the neglect of African culture, knowledge and values. This has developed to the extent that majority of graduates of the science programmes do not perceive the activities in their local communities and the time-tested knowledge of its practitioners as 
anything worth paying attention to, a situation that has been described as cultural subversion (Peters, 2000) or cultural imperialism (Jegede, 1995).

\section{Multicultural view of science}

One of the current emerging paradigms in Science Education is the multicultural perspective of science where culture is seen as the norms, values, beliefs, expectations and conventional actions of a group (Phelan, Davidson and Cao, 1991; Aikenhead 1995). This trend is informed by the work of many researchers including Jegede and Okebukola (1990, 1991) whose findings provide compelling reasons for us to consider the implications of taking a multicultural perspective on science education on the continent. This perspective recognizes Western Science as a subculture of Western culture, and also as one of the many sciences of the world and not the only science. Each culture is deemed to have its own science, a system for adapting to its environment (Brown-Acquaye, 2001). Thus, one can talk about African science, Western science, Chinese science, Indian science and Japanese science. Within these broad classifications are subcultures such as schools, classrooms, industries and job, political, social, economic, and ethnic groupings and families, with their own knowledge and know-how, and therefore their own science. School science and its associated applications in industry are closely associated with the subcultures of western science.

\section{The informal sector}

Prominent among the other subcultures, in particular the subculture of African Science is the informal sector of a nation's economy. The informal sector may be broadly characterized as consisting of units engaged in the production of goods or services with the primary objective of generating employment and incomes to the persons concerned. These units typically operate at a low level of organization, with little or no division between labour and capital as factors of production and on a small scale. Labour relations - where they exist - are based mostly on casual employment, kinship or personal and social relations rather than contractual arrangement with formal guarantees.

The informal sector is made up of people who are identified by a set of knowledge, norms, beliefs, values, expectations and conventional actions and thus constitute a subculture with its own science, the informal science. Informal science as used here, refers to the corpus of knowledge, information and know-how practised in the informal sector of the economy and generally handed down through the apprenticeship system. The activities of the informal sector span over a wide spectrum including food production, food processing, tailoring, wood processing, metal fabrication and repairs, shoe making and repair, motor fitting and bodywork repairs, construction, repair services, handicrafts, pottery, trade, restaurants and transport operations. These activities are rich in science and technology ideas, concepts and principles. These activities, however, tend to be largely ignored, rarely supported, often regulated and sometimes actively discouraged. 
We may note that informal science consists of three subcategories of science. Ogawa (1995) identified two of them, namely, personal science and indigenous science, where personal science refers to the preconceptions and science experiences of an individual. Indigenous science is the science knowledge of long resident people in a given culture. The practitioners continue to use time-honoured traditional (ancestral) practices. Examples are blacksmithing, kente weaving and pottery. The third level of informal science relates to the science knowledge of practitioners like motor fitters, vulcanizers, watch and radio repairers, as well as those using improved indigenous practices. The activities of these people are neither indigenous nor formal but seem to combine elements of both. This we wish to recognize as "way-side science" or "informal science proper". The practices and activities in "way-side" science relate in someway to conventional science practices. For example, the use of an electric milling machine makes traditional maize milling a wayside science.

\section{Formal and informal science integration}

Formal and informal sciences are not mutually exclusive, and can therefore reinforce one another. Each has its strengths and weaknesses, which can be capitalized on through the process of fusion. Western thought is often closed, by premises of intellectual superiority, to radical cross-cultural reflection (Peters, 2000). Yet we have reached a stage where science has to open its knowledge to other forms of knowledge. The multicultural perspective for science education recognizes conventional science teaching as an attempt at transmitting a scientific subculture to students and learning as the acquisition of a scientific subculture. There are, hence, the inherent border crossings between students' life world subcultures and the subcultures of science during science instruction. Using this metaphor of cultural border crossings, the African student has the problem of crossing from his/her informal science subcultures to the formal science subcultures. Since informal science is not part of the school curriculum, the student is left on his/her own to negotiate the borders of formal science. Dynamic links between the formal and informal science will reduce the trauma associated with border crossings and will also enable students to move in and out of the formal and informal science subcultures. Many science educators have called for the mainstreaming of informal science in formal science programmes (Yakubu, 1992; Anamuah-Mensah, 1998; Olorunmaiye, 1999).

\section{Benefits to integration}

Informal science activities can be used to illustrate and amplify science principles and theory and thereby help students gain a better understanding of formal science. For example, the porous earthenware pot used in storing water in rural homes can be used to illustrate evaporative cooling (an air conditioning process) and heat and mass transfer processes (Olorunmaiye, 1999). Using elements of the informal sector will also direct the minds of students to the materials and processes that are in their surroundings and, which most often are taken for granted instead of focusing on imported things, a role formal science has played very well. Giving recognition and equal status to informal science can lead to emancipator pedagogy. 
Introducing informal science activities in the science curriculum can lead to the demystification of science and make science learning more exciting and relevant to the students and thus improve the culture of science of the populace. The school will not have to use the limited funds to purchase certain materials that can be readily obtained in the local environment. Integrating informal science knowledge into formal engineering programmes can contribute to the innovation of informal technologies (e.g. motor fitting, vegetable oil extraction, blacksmithing), upgrading of the practice, and transfer of technology, which can reduce the hazardous nature of the work involved, especially for women, and increase productivity for the operators who rely on these technologies for their livelihood. Such locally developed technologies will tend to be cheaper than imported ones. Apart from improving the production processes, the integration of informal and formal science knowledge can trigger a new dynamism in economic activities in the sector. Also, the study of local medicinal plants in the Departments of Pharmacy in our institutions of higher learning can help in adding value to the drugs and other medications produced by our indigenous medical practitioners (herbalists, fetish priests and priestesses), and lead to the

production of new knowledge. It is noted that without the input of indigenous science many valuable medicines used today would not exist. By using indigenous knowledge of herbalists, bio-prospectors have the opportunity to increase the success rate in trials from one in 10,000 samples to one in two. It is estimated that indigenous knowledge increases the efficiency in screening plants for medicinal properties by more than $400 \%$ (Prakash, 2000). This type of development based on fusion of local knowledge of medicinal plants to conventional science in our universities is sustainable.

Another example is the infusion of management practices used by traditional farmers in the school agriculture curriculum to help prevent deforestation, soil erosion, drought and declining productivity, which result in famine in African countries. These management practices include agronomic practices such as terracing, contour bonding, fallowing, organic fertilizer applications, crop rotation and multi-cropping, indigenous soil and water conservation, soil fertility and indigenous soil taxonomies. It is clear that the integration of informal science and formal science has the potential of generating sustainable development. What obstacles are likely to prevent the incorporation of informal science in conventional science?

\section{Constraints to informal/formal links}

The effective integration of informal science into formal science can only be achieved with the removal of constraints that are inherent in the two subcultures of science. The constraints may be found in the differences between formal and informal science and the perceptions held by people, among which are:

- $\quad$ The perception of many scientists and science educators that formal science is universal, objective, authoritarian, value free, infallible and unchangeable. 
- The perception that informal science is inferior and is full of superstitions and myths.

- Reluctance of authors and curriculum developers to include the contributions of informal science in science textbooks and syllabuses.

- The communication gap between practitioners of informal science and their counterparts among scientists and technologists.

- The secrecy associated with informal science practitioners.

- Informal science practices differing from one country to another. Each African country has a large number of these practices. However, these have not been studied.

- Lack of a science and technology policy framework that recognizes indigenous knowledge systems as science.

\section{Attempt at integration}

Since the traditional educational system in sub-Saharan African countries was supplanted by the colonial education system with its values, content and practices, no serious attempt has been made to bring back Africa's culture into the educational process. What is observed is the occasional spicing of the content of a lesson with specific local examples. A pan-African organization that has taken a bold step in this direction is the African Forum for Children's Literacy in Science and Technology (AFCLIST) based in South Africa, which has as one of its missions, the popularization of science and technology in Africa through the mainstreaming of indigenous science into formal science teaching. AFCLIST has set up a node of excellence, the Centre for School and Community Science and Technology Studies (SACOST), at the University of Education, Winneba, Ghana, and a sub node at the University of Swaziland to promote a dynamic integration between the two cultures of science. These centres encourage endogenous development of science through the integration of community knowledge and know-how with conventional science throughout sub-Saharan Africa. The centres are mandated to develop research competences in local people through post doctoral, graduate, undergraduate and individual research projects that relate to informal science knowledge, indigenous science knowledge and modern manufacturing knowledge. At the centres the findings are used to develop multimedia teaching/learning materials that ensure that the integration of formal science with other knowledge for use in school science teaching.

The Centre at Winneba, SACOST, has established permanent agreement with the National Board for Small Scale Industries (NBSSI) and the Ghana Regional Appropriate Technology Industrial Service (GRATIS) to develop materials for schools, and ensure that students have relevant hands-on experiences through attachments at the regional networks of Intermediate Technology Transfer Units (ITTUs) set up to help develop informal technologies in the country through training and improvement in the technologies. It is noteworthy that the concern for linking formal and 
informal science and technology activities is not limited to Africa but cuts across other continents such as North America and Australia. For example, a groundbreaking step to mainstream informal science knowledge into formal science has been undertaken by the University College of Cape Breton in Nova Scotia, Canada, where a four year Bachelor of Science Community Studies (BScCS) has been instituted. This programme is intended to bring together the indigenous knowledge and know-how of aboriginal people, and the most current knowledge from the natural and cognitive sciences.

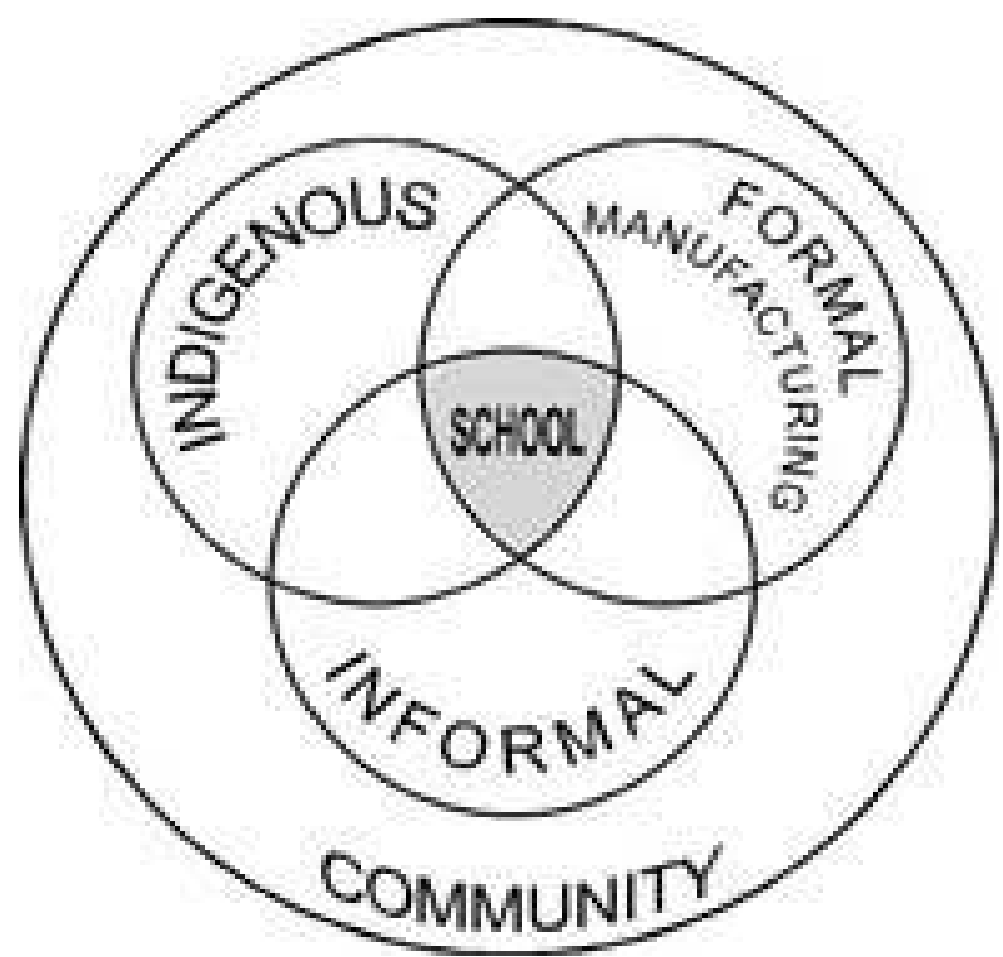

Fig. 1 Model of the relationship of indigenous, informal and formal economic activities on school science and technology education

Fig. 1 is a framework for bridging school and community science and technology. The community has four (4) major dimensions or operating areas each of which constitutes a group with shared interests, values and modes of operation. These can be seen in the Venn diagram in Fig. 1. These four (4) dimensions are school, indigenous, informal and formal. The figure focuses on the school as the central component in the model. This integration process is a triangular process involving indigenous, informal and formal within the community or larger socio-economic and cultural context. The indigenous, informal and formal economic activities constitute the workplace where there is practical application of science and technology. Thus indigenous science, informal science and formal science activities exist in the areas of the economy. It is recognized that the central component of the model, the school, has received much attention with studies done on classroom interactions among teachers, students and school environment. However, not much study has been done on the indigenous, informal and 
formal economic activities. Studies on how the school impacts on the community and workplace, specially indigenous, informal and formal workplace activities have been negligible. Similarly the impact of the community activities on school science and technology education has received little attention. It is important to know how the different dimensions relate to each other in any one country and how this relationship can be used to bring about sustainable development. Three main modes of integration or relationship can be envisaged. These are the non-integrated mode, partially integrated mode and fully integrated mode.

The school is intertwined with the socio-political, economic and cultural context of the community. The subculture of the school is reconciled with societal sub cultures. For the model relation, there is a large overlap between the school and the three sectors making it possible for schools to accommodate indigenous, informal and formal science in their science and technology curriculum. Obviously, there is a two-way interaction between school science and technology and the Community Science and Technology that is found in informal sector, indigenous knowledge and formal manufacturing industries. There is communication among the 3 sectors and the school. There is continuity, and the different sectors influence each other. The formal manufacturing can interact and influence the informal and indigenous activities and improve on their performance and may eventually absorb some of them into the formal manufacturing system. The informal activities can in turn provide support for the formal sector through e.g. marketing products or producing items such as machine parts for formal manufacturing industries, and the provision of raw materials for some industries.

The schools need to respect the indigenous science and technology and informal activities and vice versa, each being aware of the difference among them. The different dimensions or subcultures should be perceived to be of equal value even though it is not being claimed that there will be an exact balance between them. It is believed that the burden of integration will be shared by all subcultures with the school taking the lead. One of the benefits of the integrated mode will be to enhance or facilitate the transition from school to work either in the informal or formal sector of the economy. Students in a programme that incorporates other dimensions will learn to operate in both the school and non-school cultures. They will recognize the strengths and weaknesses among the different cultures - school culture, informal, indigenous and formal cultures. This will enhance the utilization and transfer of concepts and strategies from one to the other, especially from the non-school dimensions (or workplace) the life world culture to the school curriculum. Such situation will allow for the cross fertilization of ideas and techniques that will help in the enrichment and improvement of the science and technology in the informal and indigenous sectors.

\section{Conclusion}

Many aspects of informal science knowledge have suffered serious erosion overtime because of the negative attitude that local people were made to develop towards it. However, current scientific knowledge recognizes the importance of indigenous knowledge in areas such as biodiversity, 
agriculture and medicine. Modern scientific knowledge and traditional knowledge should be brought closer together in interdisciplinary project dealing with the links between culture, environment and development. Furthermore, modern science does not constitute the only form of knowledge, and that closer links need to be established between this and other forms, systems and approaches to knowledge, for their mutual enrichment and benefit. Traditional societies have nurtured and refined systems of knowledge of their own; they harbour information as yet unknown to modern science. A closer linkage between science and other knowledge systems is expected to bring important advantages to both sides (UNESCO, 2000).

The interface of formal and informal science can bring about sustainable developments and poverty alleviation. This points to the need to recognize informal and formal science as complementary rather than contradictory, even though there are fundamental differences. There is the need for commitment from governments to encourage an effective dialogue between scientists, technologists and informal science practitioners. A commitment is also needed from curriculum developers, university lecturers, teacher trainers and teachers to accept this new vision, and endeavour to bring about an effective interface of the two knowledge systems this may demand a more thorough study of the informal knowledge systems and the use of trans-disciplinary approach.

\section{References}

Aikenhead, G.S. (1995). Towards a cross-cultural perspective on Western Students leaving Western science: Border crossings. A paper presented at the annual meeting of the NARST, St. Louis

Anamuah-Mensah J. (1998). Native Science beliefs. International Journal Science Education, 20(1); 114-125.

Brown-Acquaye, H.A. (2001). Each is necessary and none is redundant: The need for science in developing countries. Science Education, 85; $68-70$.

Erinosho, S. (2001). Providing link between indigenous/informal scientific knowledge and formal science: Implications for science teaching and learning. In: J. Anamuah-Mensah, A. Asabere-Ameyaw and M. Savage (Eds) Linking indigenous/informal science and technology to school science. SACOST, Winneba.

Jegede, O.J. (1995). Collateral learning and the eco-cultural paradigm in science and mathematics education in Africa. Studies in Science Education, 25; 97-137

Jegede, O.J. and Okabukola, P.A. (1990). The relationship between African traditional cosmology and students' acquisition of a science process skill. International Journal of Science Education, 12; 37- 47.

Jegede, O.J. Okabukola, P.A. (1991). The effect of instruction on sociocultural beliefs hindering the learning of science. Journal of Research in science Teaching, 28; 275 - 285. 
Noye, D.A. (2001). A model for integrating informal science and technology into pre-university level educational system. In J. Anamuah-Mensah, A. Asabere-Ameyaw and M. Savage (Eds) Linking indigenous/informal science and technology to school science. SACOST, Winneba.

Ogawa, M. (1995). Science Education in a multiscience perspective. Science education, 79; 583 - 593.

Olorunmaiye, J.A. (1999). Applications of indigenous technologies to engineering Education. Discov Innov., II (3/4); 127 - 130.

Peters, M. (2000). Maori/Pakeha: Education and knowledge. ACU Bulletin, $145 ; 18-20$.

Phelan, P., Davidson, A. and Cao, H. (1991). Students' multiple worlds: Negotiating the Boundaries of family, peer, and school cultures. Anthropology and EducationQuarterly, 22(2); 224 - 250.

Prakash, S. (2000). Indigenous knowledge and intellectual property rights. IK Notes, 19; 1 - 4.

UNESCO (2000). World conference on science. Science for the $21^{\text {st }}$ century: A new commitment. UNESCO: Paris

Yakubu, J.M. (1992). Indigenous Science curriculum in Ghana. Science Education International, 3(3); 14 - 19. 